\title{
High-density lipoprotein subclass and particle size in coronary heart disease patients with or without diabetes
}

Li Tian ${ }^{1,2+}$, Shiyin Long ${ }^{1,3+}$, Chuanwei $\mathrm{Li}^{4}$, Yinghui Liu ${ }^{1,2}$, Yucheng Chen ${ }^{4}$, Zhi Zeng ${ }^{4}$ and Mingde $\mathrm{Fu}^{1,2^{*}}$

\begin{abstract}
Background: A higher prevalence of coronary heart disease (CHD) in people with diabetes. We investigated the high-density lipoprotein (HDL) subclass profiles and alterations of particle size in CHD patients with diabetes or without diabetes.

Methods: Plasma HDL subclasses were quantified in CHD by 1-dimensional gel electrophoresis coupled with immunodetection.

Results: Although the particle size of HDL tend to small, the mean levels of low density lipoprotein cholesterol (LDL-C) and total cholesterol (TC) have achieved normal or desirable for CHD patients with or without diabetes who administered statins therapy. Fasting plasma glucose (FPG), triglyceride (TG), TC, LDL-C concentrations, and $\mathrm{HDL}_{3}\left(\mathrm{HDL}_{3 \mathrm{~b}}\right.$ and $\left.{ }_{3 a}\right)$ contents along with Gensini Score were significantly higher; but those of $\mathrm{HDL}-\mathrm{C}_{1} \mathrm{HDL}_{2 \mathrm{~b}+\text { preß2, }}$ and $\mathrm{HDL}_{2 a}$ were significantly lower in CHD patients with diabetes versus CHD patients without diabetes; The pre $\beta_{1^{-}}$ $\mathrm{HDL}$ contents did not differ significantly between these groups. Multivariate regression analysis revealed that Gensini Score was significantly and independently predicted by $\mathrm{HDL}_{2 a}$, and $\mathrm{HDL}_{2 \mathrm{~b}+\text { pre } \beta 2}$.

Conclusions: The abnormality of HDL subpopulations distribution and particle size may contribute to CHD risk in diabetes patients. The HDL subclasses distribution may help in severity of coronary artery and risk stratification, especially in CHD patients with therapeutic LDL, TG and HDL levels.
\end{abstract}

Keywords: Coronary heart disease, High density lipoprotein subclasses, Diabetic mellitus, Fasting plasma glucose

\section{Introduction}

The diabetes is a major contributor to coronary artery disease (CAD) morbidity and mortality. It has been reported that adults with diabetes are at a 2- to 4-fold increased risk of CAD events relative to those without DM [1-5] and are at about $60 \%$ increased risk of early mortality [6]. Features of the well documented "atherogenic lipid pattern", characterized by lowered highdensity lipoprotein cholesterol (HDL-C), and elevated serum triglycerides (TG) [7], are presented in diabetic

\footnotetext{
* Correspondence: Apolipoprotein2009@yahoo.com.cn

${ }^{\dagger}$ Equal contributors

'Laboratory of Endocrinology and Metabolism, West China Hospital, Sichuan University, Chengdu, Sichuan 610041, People's Republic of China

${ }^{2}$ State Key Laboratory of Biotherapy, Sichuan University, New building 6, \#16 Section 3, People South Road, Chengdu, Sichuan 610041, People's Republic of China

Full list of author information is available at the end of the article
}

individuals. On the other hand, it is well established that plasma concentrations of HDL-C are inversely correlated with the risk of atherosclerosis and cardiovascular disease (CVD) [8].

HDL particles are heterogeneous in size and composition. Using 1-dimensional gel electrophoresis and immunoblotting, HDL can be subdivided into pre $\beta_{1}-\mathrm{HDL}$, $\mathrm{HDL}_{3 \mathrm{c}}, \mathrm{HDL}_{3 \mathrm{~b}}$, and $\mathrm{HDL}_{3 \mathrm{a}}$ as well as $\mathrm{HDL}_{2 \mathrm{a}}$ and

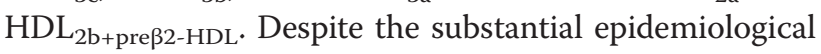
data suggesting a cardioprotective role for HDL, much remains unknown about the anti-atherothrombogenic properties of different particles that comprise this class of lipoproteins [9]. CHD patients often have increased small discoidal HDL particles and decreased large $\alpha-1$ and $\alpha-2$ HDL particles [10]. The pre $\beta_{1}$-HDL was identified as a novel and independent predictor of myocardial infarction (MI) above and beyond traditional CHD risk

\section{Biomed Central}

(c) 2012 Tian et al.; licensee BioMed Central Ltd. This is an Open Access article distributed under the terms of the Creative Commons Attribution License (http://creativecommons.org/licenses/by/2.0), which permits unrestricted use, distribution, and reproduction in any medium, provided the original work is properly cited. 
factors [11]. Other study showed that small HDL particle size was associated with an increased CHD risk, but this association was largely explained by traditional risk factors [12]. The progressive insulin resistance(IR) was associated a decrease in HDL size as a result of depletion of large $\mathrm{HDL}_{2 \mathrm{a}}$ and $\mathrm{HDL}_{2 \mathrm{~b}}$ particles and a modest increase in small HDL. The HDL subclass pattern is consistent with impaired reverse cholesterol transport (RCT) in IR individuals [13]. Considering that high-risk individuals are often treated with statins, development of diagnostic and treatment strategies to study and target HDL metabolism must involve not only the absolute concentration of HDL-C, but also the functional properties of HDL particles [14]. Which might provide more useful information for risk stratification in potentially high-risk individuals and particularly in those patients treated with lipid-altering therapy. In this study, we examined the HDL subclasses distribution profile in CHD patients with or without diabetes by onedimensional gradient gel electrophoresis.

\section{Subjects and methods Subjects}

Two hundred and twelve patients with established CHD participated in this study (These patients who were hospitalized in cardiovascular department of West China Hospital, Sichuan University). Quantitative coronary angiography (QCA) was performed at the Cardiology Department of the West China Hospital, Sichuan University. Diagnosis was based on clinical history and was confirmed by QCA. The results of angiographic examination were regarded positive for coronary atherosclerosis only if one or more major coronary arteries (right coronary, left main coronary, left anterior descending, and circumflex) had at least $50 \%$ stenosis of the luminal area. All angiograms were evaluated by two experienced physicians blinded to the study, and the severity of coronary artery disease was assessed by using the Gensini score system [15] which grades narrowing of the lumens of the coronary arteries as: 1 for $1-25 \%$ narrowing, 2 for 26-50\% narrowing, 4 for $51-75 \%, 8$ for $76-90 \%, 16$ for $91-99 \%$ and 32 for a completely occluded artery. This score is then multiplied by a factor according to the importance of the coronary artery as follows: 5 for a left main stem (LMS) lesion, 2.5 for proximal left anterior descending artery (LAD) and proximal circumflex artery (CX) lesions, 1.5 for a mid-LAD lesion, and 1 for distal LAD, mid/distal CX and right coronary artery lesions. The multiplication factor for any other branch is 0.5 . Female subjects were only included in the study if they were postmenopausal or surgically sterile. According to the World Health Organization (WHO) 1999 criteria [16], a person with a prior history of diabetes was classified as previously diagnosed diabetes regardless of the glucose levels, and Exclusion criteria included: unstable/ uncontrolled clinically significant diseases, uncontrolled primary hypothyroidism, nephrotic syndrome, renal dysfunction, or clinically significant hematology abnormalities. Additional exclusion criteria were the presence of active liver disease or hepatic dysfunction, consumption of more than 14 alcoholic drinks per week, immunosuppressive agents, and smoked cigarettes. Patients were maintained on other medications throughout the study, with no change, including calcium channel blockers, beta blockers, glucose-lowering, diuretics and other antihypertensive therapy. Written informed consent was obtained from the patients for publication of this report and any accompanying images.

150 patients with CHD receive atorvastatin treatment at $20 \mathrm{mg} /$ day for 4 weeks, and other $62 \mathrm{CHD}$ patients receive simvastatin at $40 \mathrm{mg} /$ day for 3 weeks. Blood samples were collected from subjects, after a $12 \mathrm{~h}$ overnight fast, into tubes containing 0.1\% EDTA.

\section{Blood samples}

Fasting blood samples were collected into tubes containing EDTA before the percutaneous intervention and centrifuged at $3000 \mathrm{rpm}$ for $20 \mathrm{~min}$ at $4^{\circ} \mathrm{C}$ to obtain plasma. Then it was stored at $4^{\circ} \mathrm{C}$ and used within $24 \mathrm{~h}$ for lipid and apolipoprotein analyses. An aliquot of plasma was stored at $-70^{\circ} \mathrm{C}$ for the determination of HDL subclasses.

\section{Plasma lipid and apolipoprotein analyses}

Fasting plasma concentrations of TG and total cholesterol (TC), HDL-C, and low density lipoprotein cholesterol (LDL-C) along with FPG, apoA-I, apoB-100 values were measured using automated standardized by Clinical Laboratory of West China Hospital, Sichuan University.

\section{HDL subclasses analyses}

ApoA-I contents of plasma HDL subclasses were determined by 1-dimensional gel electrophoresis coupled with immunodetection for apoA-I which developed and modified at the Laboratory of Endocrinology and Metabolism, West China Hospital, Sichuan University.

\section{Materials and equipment}

The acrylamide was obtained from Serva, TRIS from CA, bisacrylamide, boric acid, ammonium persulfate, sucrose and TEMED from Merck, PVDF membrane from Millipore. The gel apparatus included the BioRAD MiniPROTEAN 3 system, the LKB gradient maker, the LKB peristaltic pump, the BioRAD thermostatic circulator.

\section{Nondenaturing Polyacrylamide GGE of HDL Gel casting}

Polyacrylamide gradient gels were cast using a 2-chamber gradient mixer. The Casting Frame, when placed on the 
benchtop, evenly aligns and secures the Spacer Plate and the Short Plate together to form the gel cassette sandwich prior to casting (BioRAD Mini-PROTEAN 3 system ,1.0$\mathrm{mm}$ spacers, 10 -well combs). Then, $3.5 \mathrm{ml}$ of the $2 \%$ acrylamide solution and $3.5 \mathrm{ml}$ of a $30 \%$ acrylamide solution were poured into the 2 chambers of the gradient mixer. The acrylamide gradient was formed by allowing the gradient mixture to fill the gel casting cassette from the bottom during by hydrostatic pressure. The Casting Stand secures the Gel Cassette Assembly during gel casting. When the gradient had been formed, $1 \mathrm{ml}$ of distilled water was added manually. The distilled water was added slowly with a Pipette Pasteur, taking extreme care to keep a constant flow and to avoid any stirring of the gradient. Gels were then left to polymerize at room temperature, after which they could be stored under moist conditions at $4^{\circ} \mathrm{C}$ refrigerator for no longer than 1 week.

\section{Electrophoresis}

Preelectrophoresis (30minutes at $70 \mathrm{~V}$ ) and electrophoresis were performed by using Tris, boric acid, and $\mathrm{Na}_{2}-$ EDTA (pH 8.4) as running buffer. Whole serum (50 $\mu \mathrm{l})$ was mixed with $25 \mu \mathrm{l}$ of sucrose and a total volume of $10 \mu \mathrm{l}$ of sample was applied to each well. The $10 \mu \mathrm{l}$ of reference proteins (HMW Calibration for Native Electrophoresis, GE Healthcare UK Ltd., Buckinghamshire, England) were run on gel. Wells closest to the edges of the gel were not used. Electrophoresis was conducted at $70 \mathrm{~V}$ for 30 minutes, $100 \mathrm{~V}$ for $6 \mathrm{~h}$ and $200 \mathrm{~V}$ for $14 \mathrm{~h}$.

\section{Western blotting}

After electrophoresis, plasma proteins and reference proteins were electroretically transferred to PVDF membranes, stained with $0.1 \%$ ponceau $S$, and the position of reference protein bands labeled by pencil, and distained by diffusion, the membrane was blocked with 5\% BSA and incubated with horseradish peroxidase-labeled goat antihuman apoA-I-IgG polyclonal antibody which was prepared at the apolipoprotein Research Laboratory, West China Medical Center, Sichuan University overnight at $4^{\circ} \mathrm{C}$. The membrane was washed three times. The relative concentration of each subclass was calculated as the percentage of plasma apoA-I (\%) according to the density of each spot (BioRAD Imaging System Flier). The relative concentration of each HDL subclasses was calculated as the percentage of total plasma apoA-I according to the density of each spot. Particle diameters of the HDL subclasses were assessed by comparing the mobility of the sample with the mobility of calibration standard using a standard curve that included thyroglobulin, ferritin, catalase, lactate dehydrogenase, and bovine serum albumin (HMW Calibration for Native Electrophoresis, GE Healthcare UK Ltd., Buckinghamshire, England). Then, the relative percent concentration of each HDL subclass was multiplied by the apoA-I concentration in the individual samples, respectively, to yield the relative concentrations of each HDL subclass of apoA-I (in $\mathrm{mg} / \mathrm{L}$ ). The inter-assay variation $(n=5)$ of the specific HDL subclasses was 9.6\% (Pre $\left.\beta_{1}-\mathrm{HDL}\right), 8.5 \%\left(\mathrm{HDL}_{3 \mathrm{c}}\right), 6.8 \%\left(\mathrm{HDL}_{3 \mathrm{~b}}\right), 10.3 \%\left(\mathrm{HDL}_{3 \mathrm{a}}\right)$, 9.9\% $\left(\mathrm{HDL}_{2 \mathrm{a}}\right)$, and $8.3 \%\left(\mathrm{HDL}_{2 \mathrm{~b}+\operatorname{Pre} \beta 2-\mathrm{HDL}}\right)$, respectively. The intra-assay variation $(n=5)$ of the specific HDL subclasses was $2.1 \%$ (Pre $\left.\beta_{1}-\mathrm{HDL}\right), \quad 2.0 \% \quad\left(\mathrm{HDL}_{3 \mathrm{c}}\right), \quad 1.6 \%$ $\left(\mathrm{HDL}_{3 \mathrm{~b}}\right), 2.4 \%\left(\mathrm{HDL}_{3 \mathrm{a}}\right), 2.3 \%\left(\mathrm{HDL}_{2 \mathrm{a}}\right)$, and $1.9 \%\left(\mathrm{HDL}_{2 \mathrm{~b}}\right.$ $+\operatorname{Pre} \beta 2-\mathrm{HDL})$, respectively.

\section{Statistical analyses}

Kolmogorov-Smirnov statistics was used to test normality of distributions of plasma lipids, lipoproteins, HDL subclasses, and clinical parameters. For analysis, nonGaussian-distributed data were transformed using the natural logarithm to approach a Gaussian distribution. All values were presented as mean \pm S.D. The significant differences between two groups were analyzed by t-test. Pearson correlation analysis was used to estimate the association between plasma parameters and the changes in HDL subclasses profile among CHD with diabetes patients. A multiple regression analysis was also preformed the relationship between changes in coronary stenosis, and plasma lipids, lipoproteins as well as the contents of HDL subclasses. Differences were considered significant at $P<.05$. All statistical analysis was performed using the statistical package SPSS Version 15.0 (SPSS Inc).

\section{Results}

The one-dimensional gel electrophoresis and immunodetection method

Figure 1 shows the distributions of HDL subclasses for representative CHD and normolipidemic healthy subjects by nondenaturing 1-dimensional gel electrophoresis and immunodetection method. The high molecular protein standards (lane 1), (lane 2) from healthy normolipidemic subjects, (lane 3 and lane 4) from CHD subjects. With this method, the HDL can be separated into 6 distinct subclasses, pre $\beta_{1}-\mathrm{HDL}, \mathrm{HDL}_{3 \mathrm{c}}, \mathrm{HDL}_{3 \mathrm{~b}}, \mathrm{HDL}_{3 \mathrm{a}}, \mathrm{HDL}_{2 \mathrm{a}}$, and $\mathrm{HDL}_{2 \mathrm{~b}+\mathrm{Pre} \beta 2}$, according to their particles size.

Figure 2 presented that the liner relationship between the HDL subclasses $\left[p r e \beta_{1}-\mathrm{HDL}(\mathrm{r}=.95)\right.$ and $\mathrm{HDL}_{2 \mathrm{~b}+\text { pre } \beta 2}$ $(\mathrm{r}=.98)$ ]determined by using 1D-PAGGE associated with immunodection and those by using 2D-PAGGE associated with immunodection is stronger.

Baseline characteristics and plasma lipid, apolipoprotein along with HDL subclasses distribution Profiles in CHD patients with and without diabetes

Plasma levels of FPG, TG, TC, LDL-C, apoB-100, and the ratios of apoB-100 to apoA-I along with waist-to-hip (WHR) as well as waist and Gensini Score were 
significantly higher; in contrast, plasma levels of HDL-C $(-30 \%)$, apoA-I $(-18 \%)$ were significantly lower in CHD patients with diabetes $(n=115)$ in comparison with the CHD patients without diabetes $(n=97$; Table 1$)$. The body mass index (BMI), and Hip did not differ significantly between the CHD patients with diabetes and the CHD patients without diabetes.

What is more, plasma contents of large buoyant particles $\mathrm{HDL}_{2 \mathrm{a}}$ and $\mathrm{HDL}_{2 \mathrm{~b}+\text { pre }} 2$ were significantly decreased but those of small dense $\mathrm{HDL}_{3}\left(\mathrm{HDL}_{3 \mathrm{~b}}\right.$ and ${ }_{3 \mathrm{a}}$ ) were significantly increased in CHD patients with diabetes compared with CHD patients without diabetes.

\section{Correlation of plasma lipids, lipoproteins, apolipoproteins, and HDL subclasses contents for CHD patients with diabetes}

As shown in Table 2, in CHD patients with diabetes, plasma FPG, TG, and LDL-C levels, Gensini Score, BMI as well as apoB-100/A-I ratio were positively correlated with $\mathrm{HDL}_{3 \mathrm{a}}$, and $\mathrm{HDL}_{3 \mathrm{~b}}$ but inversely associated with $\mathrm{HDL}_{2 \mathrm{a}}$, and $\mathrm{HDL}_{2 \mathrm{~b}+\mathrm{pre} \beta 2}$. On the contrary, HDL-C levels were negatively correlated with $\mathrm{HDL}_{3 \mathrm{a}}$ and positively correlated with $\mathrm{HDL}_{2 \mathrm{a}}, \mathrm{HDL}_{2 \mathrm{~b}+\text { preß2}}$ along with pre $\beta_{1-}$

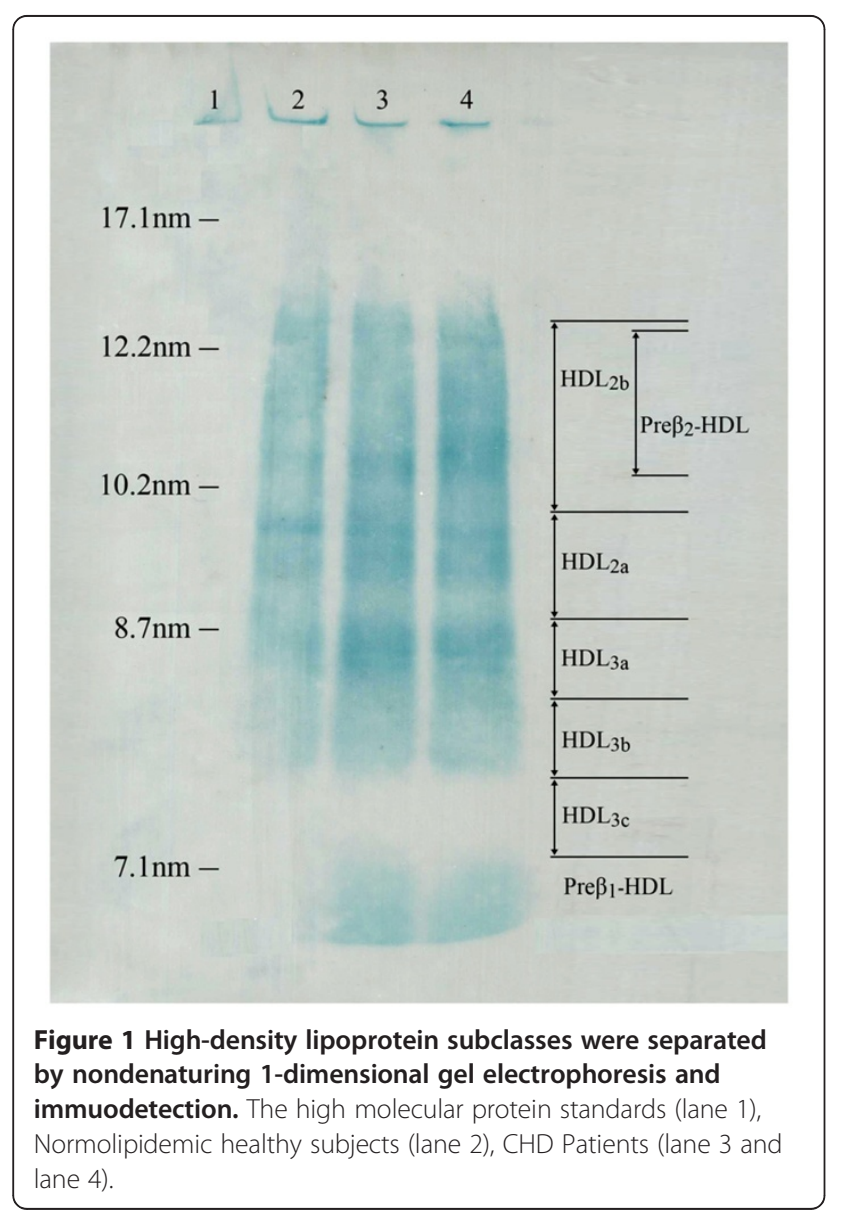

HDL. The apoA-I levels were related significantly to all HDL subclasses contents.

\section{Relationship of plasma lipids, lipoproteins,} apolipoproteins, and HDL Subclasses contents with the gensini score by Multivariate Stepwise Regression Analyses

To obtain a better understanding of the determinants for CHD patients with diabetes, stepwise multivariate regression analyses with the Gensini Score as dependent variables, and plasma lipids, lipoproteins, apolipoproteins, and HDL subclasses as independent variables were performed in this work (Table 3). The results revealed that the Gensini Score was significantly and independently predicted by TC, apoB-100, and the large-sized $\mathrm{HDL}_{2 \mathrm{a}}$ along with $\mathrm{HDL}_{2 \mathrm{~b}+\text { preß2}}$.

\section{Discussion}

HDL is not a homogeneous category of lipoproteins but consists of a set of distinct subclasses of particles that vary in size, shape, density, surface charge, and composition. Nondenaturing polyacrylamide gradient gel electrophoresis (PAGGE) has been used to isolate HDL based on particle size. Human plasma HDL includes five subclasses known as $\mathrm{HDL}_{2 \mathrm{~b}}, \mathrm{HDL}_{2 \mathrm{a}}, \mathrm{HDL}_{3 \mathrm{a}}, \mathrm{HDL}_{3 \mathrm{~b}}$, and $\mathrm{HDL}_{3 \mathrm{c}}$ in order of decreasing particle size [17]. Other methods for measuring HDL subclasses, such as nuclear magnetic resonance (NMR) spectroscopy, which assumes the detected amplitudes of spectral signals emitted by HDL subclasses of different size. This technique determines 5 subclasses of increasing size, HDL1, 2, 3, 4, and 5 corresponds to the $\mathrm{HDL}_{3 \mathrm{c}}$, 3b, 3a, 2a, 2b according to the PAGGE [18]. Agarose gel electrophoresis separates HDL into $\alpha$-, and pre $\beta$-mobility HDL, according to their different charges [19]. By combining agarose gel electrophoresis with nondenaturing PAGGE (2D-PAGGE) along with immunodetection, pre $\beta$-HDL can be further separated into pre $\beta_{1^{-}}$, and pre $\beta_{2}$-HDL except the $\alpha$-HDL used to isolate 5 subclasses. In this work, the characterization of HDL particle size (diameter) by 1D-PAGGE along with immunodetection method which developed and modified at our Laboratory. That defined 6 subclasses: pre $\beta_{1}-\mathrm{HDL}, \mathrm{HDL}_{3 \mathrm{c}}$, $\mathrm{HDL}_{3 \mathrm{~b}}, \mathrm{HDL}_{3 \mathrm{a}}, \mathrm{HDL}_{2 \mathrm{a}}$, and $\mathrm{HDL}_{2 \mathrm{~b}+\text { pre } \beta 2}$ (Figure 1). Pre $\beta_{1^{-}}$ HDL has an apparent molecular mass of $60-70 \mathrm{kDa}$ and a diameter of $5-6 \mathrm{~nm}$ [20]. Therefore, the pre $\beta_{1}-\mathrm{HDL}$ can be separated easily from the other HDL subclasses components. On the other hand, because of the diameter of pre $\beta_{2}-\mathrm{HDL}(10.2-12.37 \mathrm{~nm})$ was similar to that of $\mathrm{HDL}_{2 \mathrm{~b}}$ $(9.8-12.97 \mathrm{~nm})$, they overlapped each other. In this context, we used to add up the pre $\beta_{2}-\mathrm{HDL}, \mathrm{HDL}_{2 \mathrm{~b}}$ defined as $\mathrm{HDL}_{2 \mathrm{~b}+\text { preß }}$.

Meanwhile, we have investigated the plasma HDL subclasses distribution in hyperlipidemic, and obese 


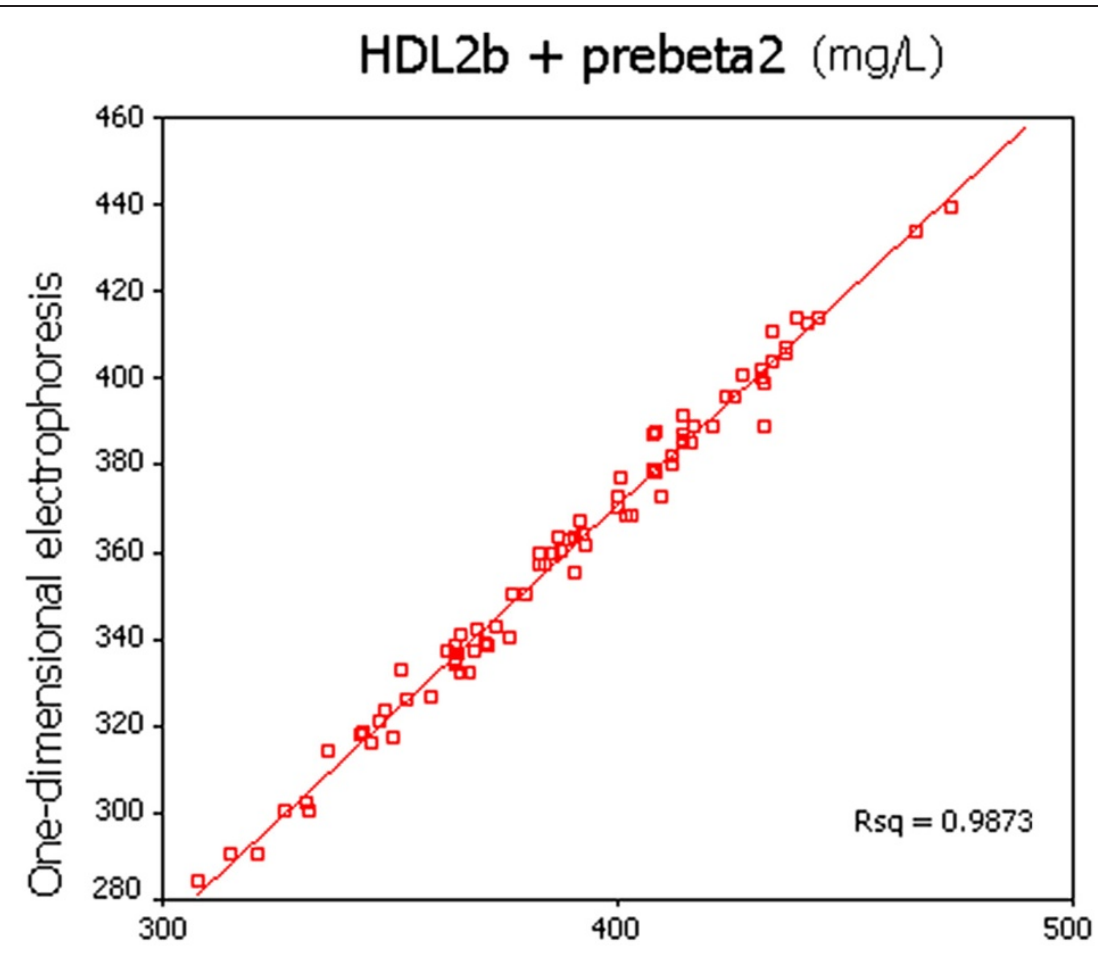

Two-dimensional electrophoresis

prebeta1 $(\mathrm{mg} / \mathrm{L})$

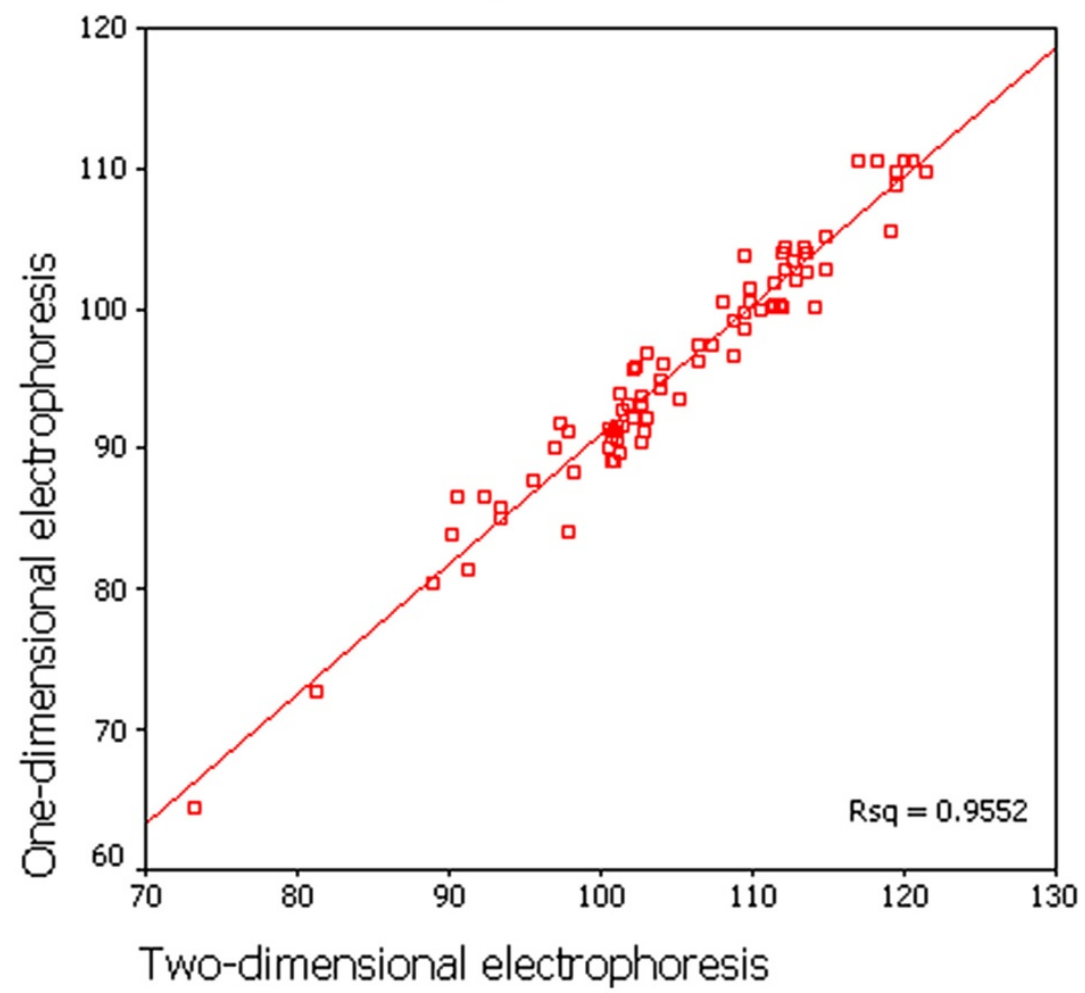

Figure 2 The scatter chart of pre $\beta_{1}-\mathrm{HDL}$ and $\mathrm{HDL}_{2 \mathrm{~b}+\text { pre } \beta 2}$ between in nondenaturing 1-dimensional and 2-dimensional gel electrophoresis coupled with immuodetection methods. 
Table 1 Clinical and Biological Characteristic of CHD Patients with Diabetes and CHD Patients without Diabetes

\begin{tabular}{|c|c|c|}
\hline & $\begin{array}{l}\text { CHD Patients with } \\
\text { Diabetes }(n=115)\end{array}$ & $\begin{array}{l}\text { CHD Patients without } \\
\text { Diabetes }(n=97)\end{array}$ \\
\hline Age(yr) & $67.1 \pm 9.7$ & $63.7 \pm 8.3$ \\
\hline Female/Male & $45 / 70$ & $53 / 44$ \\
\hline $\mathrm{SBP}(\mathrm{mmHg})$ & $135.2 \pm 20.6$ & $130.8 \pm 17.7$ \\
\hline $\mathrm{DBP}(\mathrm{mmHg})$ & $77.6 \pm 8.4$ & $75.7 \pm 7.5$ \\
\hline $\operatorname{BMI}\left(\mathrm{kg} / \mathrm{m}^{2}\right)$ & $25.0 \pm 2.6$ & $24.3 \pm 2.1$ \\
\hline Waist $(\mathrm{cm})$ & $92.4 \pm 8.6$ & $88.1 \pm 7.8^{\dagger}$ \\
\hline Hip (cm) & $94.2 \pm 6.4$ & $93.1 \pm 5.7$ \\
\hline WHR & $0.98 \pm 0.1$ & $0.94 \pm 0.1^{\dagger}$ \\
\hline Gensini Score & $53.7 \pm 9.2$ & $22.9 \pm 6.3^{\dagger}$ \\
\hline $\mathrm{FPG}(\mathrm{mmol} / \mathrm{L})$ & $9.0 \pm 1.2$ & $5.2 \pm 0.6^{*}$ \\
\hline $\mathrm{TG}(\mathrm{mmol} / \mathrm{L})$ & $2.2 \pm 0.5$ & $1.8 \pm 0.6^{*}$ \\
\hline $\mathrm{TC}(\mathrm{mmol} / \mathrm{L})$ & $4.4 \pm 1.1$ & $3.9 \pm 1.0^{*}$ \\
\hline $\mathrm{LDL}-\mathrm{C}(\mathrm{mmol} / \mathrm{L})$ & $3.4 \pm 1.0$ & $2.7 \pm 0.7^{\dagger}$ \\
\hline $\mathrm{HDL}-\mathrm{C}(\mathrm{mmol} / \mathrm{L})$ & $1.0 \pm 0.2$ & $1.3 \pm 0.2^{\dagger}$ \\
\hline ApoA-I(g/L) & $1.1 \pm 0.2$ & $1.3 \pm 0.3^{*}$ \\
\hline ApoB-100(g/L) & $0.8 \pm 0.2$ & $0.6 \pm 0.2^{*}$ \\
\hline ApoB-100/A-I & $0.7 \pm 0.2$ & $0.5 \pm 0.1^{*}$ \\
\hline $\operatorname{Pre} \beta_{1}-\mathrm{HDL}(\mathrm{mg} / \mathrm{L})$ & $92.0 \pm 9.5$ & $83.0 \pm 7.0$ \\
\hline $\mathrm{HDL}_{3 c}(\mathrm{mg} / \mathrm{L})$ & $83.9 \pm 7.4$ & $78.5 \pm 6.9$ \\
\hline $\mathrm{HDL}_{3 \mathrm{~b}}(\mathrm{mg} / \mathrm{L})$ & $170.2 \pm 20.9$ & $142.5 \pm 18.2^{*}$ \\
\hline $\mathrm{HDL}_{3 \mathrm{a}}(\mathrm{mg} / \mathrm{L})$ & $310.5 \pm 44.7$ & $272.5 \pm 38.1^{*}$ \\
\hline $\mathrm{HDL}_{2 \mathrm{a}}(\mathrm{mg} / \mathrm{L})$ & $190.5 \pm 25.8$ & $285.9 \pm 42.2^{+}$ \\
\hline $\mathrm{HDL}_{2 \mathrm{~b}+\operatorname{Pre} \beta 2-\mathrm{HDL}}(\mathrm{mg} / \mathrm{L})$ & $311.9 \pm 52.2$ & $389.3 \pm 69.5^{+}$ \\
\hline
\end{tabular}

$\mathrm{CHD}$, coronary heart disease; BMI, body mass index; FPG, fasting plasma glucose; TG, triglyceride; TC, total cholesterol; LDL-C, low density lipoprotein cholesterol; HDL-C, high density lipoprotein cholesterol; ApoA-I, apolipoproteinA-I; ApoB-100, apolipoprotein B-100.

Data are presented as Mean \pm S.D.

${ }^{*} P<0.05,{ }^{\dagger} P<0.01,{ }^{\star} P<0.001$ vs $C H D$ with diabetic patients.

subjects by 2-dimensional gel electrophoresis associated with immunodection [21-23] and found that the contents of pre $\beta_{2}$-HDL kept the relative constant among these subjects (about $60 \mathrm{mg} / \mathrm{L}$ ). Thus, the changes in contents of $\mathrm{HDL}_{2 \mathrm{~b}+\text { preß2}}$ mainly reflect the alteration of $\mathrm{HDL}_{2 \mathrm{~b}}$ contents. Moreover, relations of the pre $\beta_{1}-\mathrm{HDL}$ and $\mathrm{HDL}_{2 \mathrm{~b}}$ +preß2 by using 1D-PAGGE associated with immunodection and 2D-PAGGE associated with immunodection, respectively were explored, and the results revealed that the pre $\beta_{1}$ HDL $(r=.95)$ and $\mathrm{HDL}_{2 \mathrm{~b}+\text { preß2}}(\mathrm{r}=.98)$ have a significant liner correlation between in 1D-PAGGE associated with immunodection and 2D-PAGGE associated with immunodection measuring methods (Figure 2). The other HDL subclasses contents in subjects with 1D-PAGGE associated with immunodection were similar to those in subjects with 2D-PAGGE associated with immunodection (data not shown). Based on above reasons, making use of the 1D-
Table 2 Assessment of Relationship between Plasma Lipid, Lipoprotein, Apolipoprotein and HDL Subclasses Contents in CHD Patients with Diabetes

\begin{tabular}{|c|c|c|c|c|c|c|}
\hline \multirow[b]{2}{*}{ FPG } & \multicolumn{6}{|c|}{ Pre $\beta_{1}-\mathrm{HDL} \mathrm{HDL}_{3 c} \mathrm{HDL}_{3 b} \mathrm{HDL}_{3 a} \mathrm{HDL}_{2 \mathrm{a}} \mathrm{HDL}_{2 \mathrm{~b}+\text { preß2-HDL }}$} \\
\hline & .160 & .108 & $.390^{*}$ & $.398^{*}$ & $-.570^{* *}$ & $-.630^{* *}$ \\
\hline TG & .112 & .208 & $.243^{*}$ & $.291^{*}$ & $-.305^{* *}$ & $-.369^{* *}$ \\
\hline TC & .099 & .199 & .192 & $.210^{*}$ & .030 & .042 \\
\hline LDL-C & .140 & .120 & $.220^{*}$ & .150 & $-.252^{*}$ & $-.271^{*}$ \\
\hline HDL-C & $.176^{*}$ & -.140 & -.136 & $-.174^{*}$ & $.302^{* *}$ & $.358^{* *}$ \\
\hline Gensini Score & .102 & .134 & $.184^{*}$ & $.211^{*}$ & $-.234^{* *}$ & $-.263^{* *}$ \\
\hline BMI & .210 & .231 & .217 & $.256^{*}$ & $-.244^{*}$ & $-.270^{*}$ \\
\hline ApoA-I & $.430^{* *}$ & $.405^{* *}$ & $.453^{* *}$ & $.507^{* *}$ & $.575^{* *}$ & $.602^{* *}$ \\
\hline ApoB-100 & .116 & .128 & $.133^{*}$ & .101 & -.120 & -.123 \\
\hline ApoB-100/A-I & .240 & $.307^{*}$ & $.365^{* *}$ & $.444^{* *}$ & $-.436^{* *}$ & $-.470^{* *}$ \\
\hline
\end{tabular}

CHD, coronary heart disease; FPG, fasting plasma glucose; TG, triglyceride; TC, total cholesterol; LDL-C, low density lipoprotein cholesterol; HDL-C, high density lipoprotein cholesterol; BMI, body mass index; ApoA-I, apolipoproteinA-l; ApoB-100, apolipoproteinB-100.

${ }^{*} P<.05,{ }^{* *} P<.01$

PAGGE associated with immunodection to classify the HDL subclasses is simple and reliable.

Our study, conducted on a the CHD patients with or without diabetes, confirmed the typical alterations of lipid profile, i.e., low concentrations of HDL-C, increased levels of TG, TC, LDL-C, and FPG in CHD patients with diabetes as compared to $\mathrm{CHD}$ patients without diabetes. Meanwhile, the data presented that diabetes was associated with a profound remodel of HDL subclasses toward a less atheroprotective profile, with a reduction of the larger $\mathrm{HDL}_{2}\left(\mathrm{HDL}_{2 \mathrm{a}}\right.$ and $\mathrm{HDL}_{2 \mathrm{~b}+\mathrm{pre} \beta 2}$ ) subclasses, and an increase of the smaller, lipid poor $\mathrm{HDL}_{3}\left(\mathrm{HDL}_{3 \mathrm{~b}}\right.$, and $\left.{ }_{3 \mathrm{a}}\right)$ particles.

Compared and analyzed the prevalence of coronary artery lesions according to the angiographic Gensini Score which used to reflect the extent of coronary atherosclerosis, and the data showed that in the group of CHD patients with diabetes, the Gensini Score was significant higher than that in the group of CHD patients without diabetes (53.7 vs 22.9). Regardless of in CHD patients with or without diabetes, the mean levels of plasma lipids, and lipoproteins

Table 3 Correlations of HDL Subclasses Contents with Gensini Score in CHD Patients with Diabetes

\begin{tabular}{|c|c|c|c|c|c|}
\hline & & $\begin{array}{l}\text { Unstandardized } \\
\text { Coefficients }\end{array}$ & $\begin{array}{l}\text { Standardized } \\
\text { Coefficients }\end{array}$ & $t$ & $P$ \\
\hline & $\beta$ & $\begin{array}{c}\text { Standard } \\
\text { error }\end{array}$ & $\beta$ & & \\
\hline Gensini Score $\mathrm{HDL}_{2 \mathrm{a}}$ & -.499 & .174 & -.572 & -2.856 & 5.007 \\
\hline $\mathrm{HDL}_{2 \mathrm{~b}}$ & -.522 & .183 & -.598 & -2.872 & .006 \\
\hline $\mathrm{Apo}_{\mathrm{B} 100}$ & 67.563 & 20.153 & .677 & 2.495 & .016 \\
\hline TC & 28.304 & 8.183 & .522 & 3.459 & .001 \\
\hline
\end{tabular}

$\mathrm{CHD}$, coronary heart disease; TC, total cholesterol; HDL-C, high density lipoprotein cholesterol; $\mathrm{ApO}_{\mathrm{B} 100}$, apolipoprotein ${ }_{\mathrm{B} 100 .}$. 
were normal or desirable(as defined by the NCEP ATP-III guidelines) except the TG levels were border-line high and HDL-C levels were low for CHD patients with diabetes; whereas the contents of $\mathrm{HDL}_{2 \mathrm{~b}+\text { preß2 }}(389.3 \mathrm{mg} / \mathrm{L})$ were significantly lower for the CHD patients without diabetes than $\mathrm{HDL}_{2 \mathrm{~b}}$ added pre $\beta_{2}$-HDL contents $(378.4+56.0=434.4$ $\mathrm{mg} / \mathrm{L}$ ) for normolipidemic subjects [24]. Unlike this, we have previously investigated the plasma HDL subclasses distribution in hyperlipidemic, obese, primary diabetic mellitus (DM), and CHD patients [22,23,25-27]. The results showed that in these subjects, increased TG, TC, LDL-C, and decreased HDL-C accompanied with an increase of small-sized HDL particles and a reduction of large-sized HDL particles successively.

DM is characterized by dyslipidemia, including increased LDL-C levels, low HDL-C levels, and increased TG. Unlike other lipoproteins, HDL are not formed as mature lipoproteins, but appears in plasma as precursor particles. In CHD patients with diabetes, these subclasses undergo remodeling and interconversion by the addition and removal of their neutral lipids, phospholipids, and apo components due to the alteration of plasma lipids levels.

Several enzymes and proteins involved in HDL metabolism and remodeling are lecithin: cholesterol acyltransferase (LCAT), cholesterol ester transfer protein (CETP), hepatic lipase (HL) and lipoprotein lipase(LPL) and phospholipids transfer protein (PLTP), the ATP-binding cassette transporter $\mathrm{A} 1(\mathrm{ABCA} 1)$ and $\mathrm{G1}(\mathrm{ABCG})$. LCAT transfers the sn-2-acyl group of lecithin to cholesterol, therefore results in the generation of cholesterol esters, which are retained in the core of HDL particles, leading to the conversion of discoidal nascent HDL into spherical particles. CETP action results in transfer of CE from HDL towards triglyceriderich lipoproteins (TRLs), and reciprocal transfer of TGs from TRLs to HDL. Elevated TGs increase the CE transfer process out of HDL, resulting in CE depletion and TG enrichment of HDL and subsequent increased HDL catabolism leads to the formation of small HDL particles [28]. LPL is the rate-limiting enzyme for the hydrolysis of the TG core of TRLs, chylomicrons (CM) and VLDL, when catabolized by LPL, CM and VLDL release PL, apoA-I, cholesterol, TG, and apoCs, subsequent binding of these products to $\mathrm{HDL}_{3}$ results in the formation of $\mathrm{HDL}_{2}$ particles [29]. ABCAI is responsible for cholesterol and PL efflux towards lipid-poor or lipid-free apoA-I [30]; ABCG1 mediates cholesterol and PL efflux to mature HDL [31].

Most studies have established the action of above enzymes and protein factors associated with the increase of plasma TG, LDL-C, and decrease of plasma HDL-C levels. Hence, based on the changed in plasma lipids which leading to altered HDL subclass and particle size remodel in CHD patients with diabetes [32,33].

Meanwhile, plasma LCAT and LPL activity has been reported to be decreased in IR and $\mathrm{T}_{2} \mathrm{DM}$ subjects [34]. A decreased post-heparin plasma LPL/HL ratio is a determinant of low $\mathrm{HDL}_{2}$ cholesterol in IR. At the same time, Mauldin et al [35] could demonstrate that macrophage ABCG1 expression and function are decreased in mouse models of $\mathrm{T}_{2} \mathrm{DM}$ and $\mathrm{ABCA1}$ gene expression is severely decreased in the liver and pertitoneal macrophages of diabetic mice compared with euglycemic control mice [36]. In addition, PLTP activity in plasma is elevated in IR and $\mathrm{T}_{2} \mathrm{DM}$ in association with high plasma TG and obesity [37].

Compared with the CHD patients without diabetes, in CHD patients with diabetes, the alteration of plasma lipids levels and activities of enzymes involved in HDL particles metabolism and the receptor mediated uptake or efflux of free cholesterol(FC)/cholesterol esters(CE) towards/from HDL is modified result in altered HDL subclass and particle size.

The changes in HDL subclasses might correlate with the WHR. The present data displayed that WHR is higher significantly in CHD patients with diabetes (0.98), as compared to CHD patients without diabetes (0.94). Some studies demonstrated a negative relationship between WHR and $\mathrm{HDL}_{2}$, independent of TG and other subclasses [38]. This concords with studies by Terry et al [39] concerning $\mathrm{HDL}_{2}$, although the latter did not correct for TG and Walton et al [40] where TG were taken into account.

Type 2 diabetes is largely considered as a $\mathrm{CHD}$ "equivalent" risk category [41] and the differences in HDL subpopulations profile noted in diabetic women resembled, both qualitatively and quantitatively, those reported for male subjects with a previous CHD event [42]. Taken together these findings suggest that early alterations in HDL subpopulations profile may contribute to $\mathrm{CHD}$ risk in diabetic patients.

It was demonstrated that atorvastatin was more effective to treat lipid abnormalities and to modify the HDL subclasses profile than simvastatin, by increasing the concentration of the large, cholesterol rich, $\mathrm{HDL}_{2}$ and decreasing the concentration of the small, TG-rich, $\mathrm{HDL}_{3}$ in $\mathrm{CHD}$ patients [43]. In our study, nevertheless statins therapy could be effective in normalizing the plasma lipids phenotype, the HDL particle size tend to small in CHD patients with or without diabetes, particularly in CHD patients with diabetes. That implicated that the distribution of HDL subclasses modification lagged behind the improvement of plasma lipids levels. For the possible reason, on one side might involve in the conversion process of HDL subclasses. On the other side, it is well known that the treatment of statins had significantly effect in modulating the atherogenic lipids; but the impact of it on plasma lipoproteins metabolism is unclear, and we speculated that the compositions of plasma lipoproteins change could play a function in these, and need to further study. Meanwhile, the Pearson correlation and multivariate stepwise regression analysis supported that the Gensini Score were associated 
independently with HDL subclasses. Under this condition, our findings implication that the distribution of HDL subclasses abnormalities might be an important potential factor involved in the increased CHD risk associated with diabetic patients and arteriographic progression.

In present study, we mainly discussed the HDL subclass profiles and alterations of particle size in CHD patients with diabetes or without diabetes. The limitation of the present work is that no baseline measurements of lipids prior to beginning statin therapy, and potential mechanisms underlying the processing and/or distribution difference in HDL subclasses particles should be discussed in next study.

\section{Conclusions}

To summarize, the abnormality of HDL subpopulations distribution and particle size may contribute to CHD risk in diabetic patients. The HDL subclasses distribution may help in severity of coronary artery and risk stratification, especially in CHD patients with therapeutic LDL, TG and HDL levels.

\begin{abstract}
Abbreviations
HDL: High-density lipoprotein; CHD: Coronary heart disease; LDL-C: Low density lipoprotein; TC: Total cholesterol; FPG: Fasting plasma glucose; TG: Triglyceride; DM: Diabetes mellitus; CAD: Coronary artery disease; CV: Cardiovascular; QCA: Quantitative coronary angiography; LMS: Left main stem; LAD: Left anterior descending artery; CX: Proximal circumflex artery; WHO: World Health Organization; WHR: Waist to hip; BMl: Body mass index; NMR: Nuclear magnetic resonance; NCEP: National Cholesterol Education Program; IFG: Impaired fasting glucose.
\end{abstract}

\section{Competing interests}

The authors declare that they have no competing interests.

\section{Authors' contributions}

LT participated in the design of study and paper preparation together with editing. SYL helped to review the manuscript. CWL collected and performed data. YHL participated in drafted the manuscript. YCC performed the data acquisition and analysis. ZZ conceived of the study. MDF participated in manuscript reviewing and drafting. All authors read and approved the final manuscript.

\section{Acknowledgments}

This work was supported by the grants from Science Foundation of China Postdoctoral (Grant No. 20110491719).

\section{Author details \\ 'Laboratory of Endocrinology and Metabolism, West China Hospital, Sichuan University, Chengdu, Sichuan 610041, People's Republic of China. ${ }^{2}$ State Key Laboratory of Biotherapy, Sichuan University, New building 6, \#16 Section 3, People South Road, Chengdu, Sichuan 610041, People's Republic of China. ${ }^{3}$ Department of Biochemistry and Molecular Biology, University of South China, Hengyang, Hunan, People's Republic of China. ${ }^{4}$ Cardiovascular department of West China Hospital, Sichuan University, Chengdu, Sichuan 610041, People's Republic of China.}

Received: 13 March 2012 Accepted: 27 April 2012

Published: 15 May 2012

\section{References}

1. Lundberg V, Stegmayr B, Asplund K, Eliasson M, Huhtasaari F: Diabetes as a risk factor for myocardial infarction: population and gender perspectives. J Intern Med 1997, 241:485-492

2. Lotufo PA, Gaziano JM, Chae CU, Ajani UA, Moreno-John G, Buring JE, Manson JE: Diabetes and all-cause and coronary heart disease mortality among US male physicians. Arch Intern Med 2001, 161:242247.

3. Liao Y, Cooper RS, Ghali JK, Lansky D, Cao G, Lee J: Sex differences in the impact of coexistent diabetes on survival in patients with coronary heart disease. Diabetes Care 1993, 16:708-713.

4. Hu FB, Stampfer MJ, Solomon CG, Liu S, Willett WC, Speizer FE, Nathan DM, Manson JE: The impact of diabetes mellitus on mortality from all causes and coronary heart disease in women: 20 years of follow-up. Arch Intern Med 2001, 161:1717-1723.

5. Kannel WB, McGee DL: Diabetes and glucose tolerance as risk factors for cardiovascular disease: the Framingham study. Diabetes Care 1979, 2:120-126.

6. Miettinen H, Lehto S, Salomaa V, Māhōnen M, Niemelā M, Haffner SM, Pyörälä K, Tuomilehto J, The FINMONICA Myocardial Infarction Register Study Group: Impact of diabetes on mortality after the first myocardial infarction. Diabetes Care 1998, 21:69-75.

7. Betteridge DJ: Diabetic dyslipidaemia. Eur Clin Invest 1999, 29(Suppl 2):12-16.

8. Vega GL, Grundy SM: Hypoalphalipoproteinemia (low high density lipoprotein) as a risk factor for coronary heart disease. Curr Opin Lipidol 1996, 7:209-216.

9. Brewer HB: HDL metabolism and the role of HDL in the treatment of high-risk patients with cardiovascular disease. Curr Cardiol Rep 2007, 9:486-492.

10. Asztalos BF, Collins D, Cupples LA, Demissie S, Horvath KV, Bloomfield HE, Robins SJ, Schaefer EJ: Value of high density lipoprotein (HDL) subpopulations in predicting recurrent cardiovascular events in the Veterans Affairs HDL Intervention Trial. Arterioscler Thromb Vasc Biol 2005, 25:2185-2191

11. Guey LT, Pullinger CR, Ishida BY, O'Connor PM, Zellner C, Francone OL, Laramie JM, Naya-Vigne JM, Siradze KA, Deedwania P, Redberg RF, Frost PH, Seymour AB, Kane JP, Malloy MJ: Relation of Increased Prebeta-1 High-Density Lipoprotein Levels to Risk of Coronary Heart Disease. Am J Cardiol 2011, 108:360-366.

12. Arsenault BJ, Lemieux I, Despres JP, Gagnon P, Wareham NJ, Stroes ES, Kastelein JJ, Khaw KT, Boekholdt SM: HDL particle size and the risk of coronary heart disease in apparently healthy men and women: the EPIC-Norfolk prospective population study. Atherosclerosis 2009 206:276-281.

13. Garvey WT, Kwon S, Zheng DY, Shaughnessy S, Wallace P, Hutto A, Pugh K Jenkins AJ, Klein RL, Liao YL: Particle size and Concentration Determined by Nuclear Magnetic Resonance. Diabetes 2003, 52:453-462.

14. Rosenson RS: Functional assessment of HDL: moving beyond static measures for risk assessment. Cardiovasc Drugs Ther 2010, 24:71-75.

15. Gensini GG: A more meaningful scoring system for determining the severity of coronary heart disease. Am J Cardiol 1983, 51:606-607.

16. WHO: Definition, diagnosis and classification of diabetes mellitus and its complications. Part 1: diagnosis and classification of diabetes metlitus. Geneva: WHO; 1999. Available at: http://www.staff.ncl.ac.uk/philip.home/ who dmg.pdf. Accessible in Jan 2007.

17. Nichols AV, Krauss RM, Musliner TA: Nondenaturing polyacrylamide gradient gel electrophoresis. Methods Enzymol 1986, 128:417-431.

18. Otvos JD, Jeyarajah EJ, Bennett DW, Krauss RM: Development of a proton nuclear magnetic resonance spectroscopic method for determining plasma lipoprotein concentrations and subspecies distributions from a single, rapid measurement. Clin Chem 1992, 38:1632-1638.

19. Castro GR, Fielding CJ: Early incorporation of cell-derived cholesterol into preß-migrating high density lipoprotein. Biochemistry 1988, 27:25-29.

20. Fielding CJ, Fielding PE: Molecular physiology of reverse cholesterol transport. J Lipid Res 1995, 36:211-228.

21. Xu YH, Fu MD: Alterations of HDL subclasses in hyperlipidemia. Clin Chim Acta 2003, 332:95-102

22. Tian L, Jia LQ, Fu MD, Tian Y, Xu YH, Tian HM, Yang YY: Alterations of high density lipoprotein subclasses in obese subjects. Lipids 2006, 41:789-796

23. Gou LT, Fu MD, Xu YH, Tian Y, Yan BY, Yang LC: Alterations of HDL subclasses in endogenous hypertriglyceridemia. Am Heart J 2005, 150:1039-1045.

24. Jia LQ, Fu MD, Tian Y, Xu YH, Gou LT, Tian HM, Tian Ll: Alterations of highdensity lipoprotein subclasses in hypercholesterolemia and combined hyperlipidemia. Int J Cardio 2007, 120:331-337. 
25. WHO: Technical Report Series No. 844. Prevention of diabetes mellitus: report of a WHO Study Group. Geneva: World Health Organization; 1994.

26. Xu YH, Fu MD, Wu XW, Ren Y: Study on the content of serum HDL subclasses in type 2 diabetic patients. Chin J Diabetes 2001, 9:160-162.

27. Xu YH, Fu MD, Xu YX, Yang LC, Liu Y, Yao J: Relationship between the concentrations of plasma lipids and the contents of serum HDL subclasses in patients with coronary heart disease. J Clin Cardiol (China) 2003, 19:581-584.

28. Lamarche B, Uffelman KD, Carpentier A, Cohn JS, Steiner G, Barrett PH, Lewis GF: Triglyceride enrichment of $\mathrm{HDL}$ enhances in vivo metabolic clearance of HDL apo A-I in healthy men. J Clin Invest 1999, 103:1191-1199.

29. Eckel RH: Lipoprotein lipase. A multifunctional enzyme relevant to common metabolic diseases. N Engl J Med 1989, 320:1060-1068.

30. Rye KA, Barter PJ: Formation and metabolism of prebeta migrating, lipidpoor apolipoprotein A-I. Arterioscler Thromb Vasc Biol 2004, 24:421-428.

31. Baldan A, Tarr P, Lee R, Edwards PA: ATP-binding cassette transporter G1 and lipid homeostasis. Curr Opin Lipidol 2006, 17:227-232.

32. Rye K-A, Clay MA, Barter PJ: Remodelling of high density lipoproteins by plasma factors. Atherosclerosis 1999, 145:227-238.

33. Lee M, Kim JQ, Kim J, Oh H, Park M: Studies on the plasma lipid profiles, and LCAT and CETP activities according to hyperlipoproteinemia phenotypes(HLP). Atherosclerosis 2001, 159:381-389.

34. Knudsen P, Eriksson J, Lahdenpera S, Kahri J, Groop L, Taskinen MR: Changes of lipolytic enzymes cluster with insulin resistance syndrome. Botnia Study Group. Diabetologia 1995, 38:344-350.

35. Mauldin JP, Srinivasan S, Mulya A, Gebre A, Parks JS, Daugherty A, Hedrick CC: Reduction in ABCG1 in Type 2 diabetic mice increases macrophage foam cell formation. J Biol Chem 2006, 281:21216-21224.

36. Uehara Y, Engel T, Li Z, Goepfert C, Rust S, Zhou X, Langer C, Schachtrup C, Wiekowski J, Lorkowski S, Assmann G, von Eckardstein A: Polyunsaturated fatty acids and acetoacetate downregulate the expression of the ATPbinding cassette transporter A1. Diabetes 2002, 51:2922-2928.

37. Jauhiainen M, Metso J, Pahlman R, Blomqvist $S$, van Tol A, Ehnholm C: Human plasma phospholipid transfer protein causes high density lipoprotein conversion. J Biol Chem 1993, 268:4032-4036.

38. James RW, Brulhart-Meynet MC, Lehmann T, Golay A: Lipoprotein distribution and composition in obesity: their association with central adiposity. Int J Obes 1997, 21:1115-1120.

39. Terry RB, Wood PD, Haskell WL, Stefanick ML, Krauss RM: Regional adiposity patterns in relation to lipids, lipoprotein cholesterol, and lipoprotein subfraction mass in men. J Clin Endocrinol Metab 1989, 68:191-199.

40. Walton C, Lees B, Grook D, Worthington M, Godsland IF, Stevenson JC: Body fat distribution, rather than overall adiposity, influences serum lipids and lipoproteins in men independently of age. Am J Med 1995, 99:459-464.

41. Expert Panel on Detection, Evaluation, and Treatment of High Blood Cholesterol in Adults. Executive Summary of The Third Report of The National Cholesterol Education Program (NCEP) Expert Panel on Detection, Evaluation, And Treatment of High Blood Cholesterol In Adults (Adult Treatment Panel III). JAMA 2001, 285:2486-2497.

42. Asztalos BF, Roheim PS, Milani RL, Lefevre M, McNamara JR, Horvath KV, Schaefer EJ: Distribution of ApoA-I-containing HDL subpopulations in patients with coronary heart disease. Arterioscler Thromb Vasc Biol 2000 20:2670-2676.

43. Asztalos BF, Horvath KV, McNamara JR, Roheim PS, Rubinstein JJ, Schaefer EJ: Comparing the effects of five different statins on the HDL subpopulation profiles of coronary heart disease patients. Atherosclerosis 2002, 164:361-369.

doi:10.1186/1476-511X-11-54

Cite this article as: Tian et al:: High-density lipoprotein subclass and particle size in coronary heart disease patients with or without diabetes. Lipids in Health and Disease 2012 11:54.

\section{Submit your next manuscript to BioMed Central and take full advantage of:}

- Convenient online submission

- Thorough peer review

- No space constraints or color figure charges

- Immediate publication on acceptance

- Inclusion in PubMed, CAS, Scopus and Google Scholar

- Research which is freely available for redistribution

Submit your manuscript at www.biomedcentral.com/submit
C Biomed Central 